\title{
2 AGUA \\ La Cuenca Hidrosocial Presa Huapango, México: Un análisis de la Gestión Integrada de los Recursos Hídricos y la gobernanza en cuerpos de agua compartidos
} water and landscape

\author{
The Huapango Dam Hydrosocial Basin, Mexico: \\ An analysis of the Integrated Management of Water \\ Resources and governance in shared water bodies
}

\author{
Marta García Galván \\ Instituto de Ciencias Agropecuarias y Rurales (UAEMEX) \\ Toluca, México \\ margalvan@yahoo.com
}

Francisco Herrera Tapia Instituto de Ciencias Agropecuarias y Rurales (UAEMEX) Toluca, México fherrerat@uaemex.mx

\begin{abstract}
Resumen - Durante la época contemporánea en América Latina y el resto del mundo la problemática de la escasez, calidad, sustentabilidad y derecho al agua en cuerpos de agua compartidos se ha hecho presente. Por lo que, este trabajo analiza la gestión integrada de los recursos hídricos y la gobernanza como factores clave para resolver dichas adversidades de forma holística. En este sentido, se analiza el caso de la Presa Huapango, México, ya que es compartida por cinco municipios del Norte del Estado de México $^{1}$ : Acambay, Aculco, Jilotepec Timilpan y Polotitlán que juntos conformaron para este análisis una cuenca hidrosocial por existir una interrelación entre pobladores de aguas arriba y aguas abajo que comparten una problemática de tipo social, económico, político y ambiental que quieren resolver a través de la propuesta de creación de un Comité intermunicipal para el uso, cuidado y defensa de la presa Huapango con su Reglamento como instrumentos de política pública para iniciar acciones, proyectos y programas mediante la participación de los actores históricos, y así poder garantizar la sustentabilidad de la presa Huapango y el desarrollo integral de su región.
\end{abstract}

\begin{abstract}
During the contemporary era in Latin America and the rest of the world the problem of scarcity, quality, sustainability and the right to water in shared water bodies has been present. Therefore, this work analyses integrated water resource management and governance as key factors in resolving such adversities holistically. In this sense, the case of the Huapango Dam, Mexico, is analyzed, as it is shared by five municipalities in the North of the State of Mexico: Acambay, Aculco, Jilotepec Timilpan and Polotitlán that together formed for this analysis a basin because there is an interrelationship between upstream and downstream people who share a social, economic, political and environmental problem that they want to solve through the proposal for the creation of an inter-municipal committee for the use, care and defense of the Huapango Dam with its Regulations as public policy instruments to initiate actions, projects and programs through the participation of historical actors, in order to ensure the sustainability of the Huapango Dam and the integral development of its region.
\end{abstract}

Palabras clave: Cuenca Hidrosocial, Gestión Integrada, Gobernanza, Cuerpos de agua compartidos, Presa Huapango, México

Keywords: Hydrosocial Basin, Integrated Management, Governance, Shared bodies of water; Huapango Dam, Mexico

Información Artículo: $\quad$ Recibido: 22 febrero 2019 Revisado: 15 septiembre 2019 Aceptado: 26 octubre 2019

\footnotetext{
${ }^{1}$ El Estado de México para diferenciarlo de México como país, es una de las treinta y dos entidades federativas que forman los Estados Unidos Mexicanos y está ubicado en la región centro del país, es la entidad más poblada con 16.187.608 habs. en 2015, y la más densamente poblada con 678,80 habs/km². Instituto Nacional de Estadística y Geografía, 2018.
} 


\section{INTRODUCCIÓN}

La Gestión Integrada de los Recursos Hídricos (GIRH), es un concepto empírico que nace de la propia experiencia de campo de los profesionales. Aunque muchos de los elementos del concepto han estado presentes durante décadas, desde la primera Conferencia de las Naciones Unidas sobre el Agua en Mar del Plata en 1977, es hasta después de la Conferencia de las Naciones Unidas sobre Medio Ambiente y Desarrollo (CNUMAD) que popularmente es conocida como Cumbre de Río realizada en 1992 en Río de Janeiro, Brasil cuando el concepto de GIRH fue objeto de profundos debates que incluían sus implicaciones en la práctica por lo que la definición que da la Asociación Mundial para el Agua (GWP, por sus siglas en inglés) de la GIRH es hoy la más aceptada: "La GIRH es un proceso que promueve la gestión y el desarrollo coordinados del agua, el suelo y los otros recursos relacionados, con el fin de maximizar los resultados económicos y el bienestar social de forma equitativa sin comprometer la sostenibilidad de los ecosistemas vitales"2.

Bajo este argumento, la Global Water Partnership, señala que operativamente, el enfoque de GIRH involucra la aplicación de conocimiento de diversas disciplinas, así como las perspectivas de diversos actores para elaborar e implementar soluciones eficientes, equitativas y sostenibles a los problemas hídricos y de desarrollo. Por lo tanto, "la GIRH es una herramienta para el desarrollo y la gestión del agua de forma que hace un balance de las necesidades económicas, sociales, políticas y ambientales para asegurar la protección de ecosistemas para generaciones futuras" ${ }^{3}$.

En el mismo sentido, "la GIRH, trata de ser una respuesta en las últimas décadas a los problemas mundiales, nacionales y locales de escasez, calidad y saneamiento del agua. Se trata de un enfoque que pretende integrar el conocimiento de una diversidad de sistemas que deben considerarse en forma simultánea, bajo distintas disciplinas, concepciones, conocimientos e investigaciones" ${ }^{4}$, ya que el agua tiene muchos usos diferentes -para la agricultura, para ecosistemas saludables, para la gente y su sustento-que demandan una acción coordinada. Un enfoque de GIRH es un proceso abierto y flexible que une a tomadores de decisión de diversos sectores que repercuten en el recurso hídrico, y trae a todos los actores a la mesa para establecer políticas y decisiones balanceadas en respuesta a retos hídricos enfrentados.

Por otro lado, "la GIRH se trata de una gestión holística del agua que tiene en cuenta todas las dimensiones: el ciclo del agua completo, todos los sectores, las escalas espaciales y temporales, por lo que se fortalecen los marcos y arreglos entre actores para que se favorezca la buena toma de decisiones" 5 , ya que la GIRH sólo puede tener éxito si todos los grupos de interés como los grupos marginados y de escasos recursos, pueden

\footnotetext{
2 Integrated Water Resources Management in Action. WWAP, DHI Water Policy, PNUMA-DHI Centro para el Agua y el Medio Ambiente, 2014.

${ }^{3}$ Global Water Partnership, 2009.

${ }^{4}$ Cotler, 2004.

${ }^{5}$ Díaz, 2015.
}

participar de forma significativa en las decisiones de la gestión del agua.

Por tal motivo, la Organización para la Cooperación y el Desarrollo Económicos (OCDE) (OECD, por sus siglas en inglés) ${ }^{6}$, demuestra que no existe una solución única para los desafíos del agua a nivel mundial, sino más bien una gran diversidad de situaciones entre países y dentro de éstos. Por ende, las respuestas deben adaptarse a las especificidades territoriales y reconocer que la GIRH y la gobernanza son altamente dependientes del contexto e importantes para adaptar las políticas del agua a cada lugar geográfico.

En consecuencia, “la noción de gobernanza, cuando se aplica al agua, se refiere a la capacidad de un sistema social para movilizar las energías, de manera coherente, para un desarrollo sostenido de los recursos hidráulicos.

La noción contiene la capacidad de diseñar políticas públicas (y movilizar los recursos sociales que las sustenten) que sean socialmente aceptadas, y que tengan como meta el desarrollo y el uso sostenido de los recursos hidráulicos, así como lograr que su implementación se lleve a cabo de manera efectiva por los diferentes actores/grupos de interés involucrados en el proceso, por lo que la gobernanza es un concepto más incluyente que el gobierno per se; abarca la relación entre una sociedad y su gobierno"7.

La gobernanza del agua consiste primordialmente en la buena gestión del agua y la participación social en la conformación de las decisiones en torno a este recurso. El enfoque de gobernanza propone una serie de elementos cuya articulación permite construir soluciones viables, ya que los mayores riesgos hídricos que enfrentamos hoy se asocian con la creciente degradación de los recursos naturales de las cuencas, la dinámica poblacional, el crecimiento urbano, la inadecuada ordenación territorial y la consecuente ocupación de zonas de riesgo, la sobreexplotación de los acuíferos, los efectos de las sequías e inundaciones, así como la vulnerabilidad de la infraestructura y operación de los sistemas hidráulicos. Tales factores se están agravando por los efectos del cambio climático y se prevé que puedan agudizarse en el futuro ${ }^{8}$.

En este sentido se considera que una gran parte de los problemas de gestión de una cuenca son producto de la falta de coordinación entre distintas instituciones aparece como clara la necesidad de diálogo y entendimiento de todos los niveles de administración involucrados, como las autoridades locales y la sociedad civil, por lo que implementar soluciones para la mejora de la gestión del agua, debe tener una dimensión nacional, internacional y regional, toda vez que muchos de los cuerpos de agua de los que dependen sociedades enteras son transfronterizos ${ }^{9}$.

La vigencia de la soberanía nacional se manifiesta en la gestión de cuencas compartidas en donde todavía resta mucho por hacer en materia de cooperación y gestión conjunta siguiendo los principios del desarrollo sostenible, del enfoque por ecosistemas y de una gobernanza efectiva. Hasta tanto no se implemente una gestión conjunta, las

\footnotetext{
6 OCDE, 2015.

${ }^{7}$ Rogers y Hall, 2003.

${ }^{8}$ Galindo y Jiménez, 2018.

${ }^{9}$ Aguilar y Alejandro, 2009.
} 
poblaciones más vulnerables continuarán sufriendo los efectos negativos de un manejo ineficiente del agua.

Resulta necesario entonces elucidar estrategias más efectivas, como también políticas e instrumentos jurídicos que promuevan una gobernanza conjunta de cuencas transfronterizas, de forma tal que se conserve la calidad del agua, se establezcan los caudales ambientales para que los ecosistemas continúen prestando sus servicios esenciales, se utilicen en general los recursos en forma más racional, y se desarrolle en forma sostenible y holística (la región del cuerpo de agua compartido).

Por lo que la gestión integrada del agua y la gobernanza son reconocidas hoy en día por gran parte de la comunidad internacional como un componente esencial de una estrategia global para mejorar la distribución del agua y como pilar fundamental para potenciar el desarrollo político, ambiental, económico y social.

Por tal motivo, la gestión integrada de los recursos hídricos y la gobernanza son una vía para resolver problemas de cuerpos de agua compartidos, ya que permiten llegar a acuerdos entre todos los actores para beneficio común, lograr la sustentabilidad y el desarrollo de las regiones como se expone en este trabajo que está estructurado en cuatro apartados: metodología, resultados, conclusiones y bibliografía.

En el primer apartado de este artículo se plantea la metodología que consistió en trabajo de gabinete y de campo. Entendido el primero como la revisión bibliográfica, hemerográfica y bases de datos electrónicos para obtener información relevante del tema, y el segundo corresponde al método etnográfico.

En los resultados se hallaron cuerpos de agua compartidos a nivel mundial que pueden ser estudiados desde esta perspectiva, se delimitó el área de estudio como Cuenca Hidrosocial Presa Huapango (CHPH) y se detectó la problemática ambiental, social, económica y política de la cuenca, además se descubrieron cinco mapas de actores ya establecidos en la CHPH y se identificaron los principios de gobernanza: Identidad, cultura, autogestión, poder, relaciones intermunicipales, gobernabilidad, cooperación, participación social, democracia y voluntariedad de la sociedad; todo esto permitió elaborar la propuesta de creación de un Comité Intermunicipal con su Reglamento.

En las conclusiones, se señala que los cuerpos de agua compartidos a nivel mundial presentan problemas de carácter ambiental, social, económico y político que deben ser atendidos desde un enfoque de gestión integrada de los recursos hídricos y de gobernanza, ya que es ahí donde las estructuras históricas permiten la cooperación de los distintos actores para resolver problemas comunes de forma integral.

Finalmente, se hace alusión a la bibliografía que se utilizó para la elaboración del presente documento.

\section{METODOLOGíA}

Para la realización de esta investigación se hizo uso del trabajo de gabinete y de campo que fue sistematizado a través de la triangulación del marco teórico, el trabajo de campo y el uso de indicadores numéricos para obtener como resultado una propuesta de Comité Intermunicipal con su reglamento.
El trabajo de gabinete consistió en la revisión bibliográfica, hemerográfica y bases de datos electrónicos para obtener información relevante del tema.

Por su parte, el trabajo de campo se hizo mediante el método etnográfico. "El método de la etnografía estudia a las culturas y sociedades para encontrar su lógica de estructura y funcionamiento. El método etnográfico se apoya en el trabajo de campo y registro in situ de roles, valores y normas a las que se hallan sujetas las comunidades para establecer relaciones con el ambiente y con otras estructuras sociales. Se divide en 3 pasos: 1. trabajo de campo in situ, 2. identificación de sistemas sociales y 3 . historias de vida, es decir, de entrevista y fuentes de información de primera mano" ${ }^{\text {10 }}$.

"En el trabajo de campo in situ, el investigador está en contacto directo con el objeto de estudio; observa de forma directa y recoge la información del paisaje y su relación con la cultura. En el caso de estudio se realiza observación con diario de campo. En él se anota la observación directa y las entrevistas. La entrevista se realiza a los llamados informantes clave, éstos son los actores que poseen información detallada y privilegiada sobre el asunto de investigación. Los argumentos vertidos por los informantes clave deben ser congruentes con la información recabada con las demás fuentes de información. No deberá haber graves inconsistencias; los hechos deben reforzar y reafirmar la información que se recaba a lo largo del proceso" ${ }^{11}$.

“La caracterización de la estructura social, también es conocida como sistema social, ya que ha demostrado ser el componente más importante para entender e identificar las formas de organización de las sociedades y de los grupos humanos. Por lo tanto, caracterizar la estructura social se vuelve fundamental para identificar los componentes más importantes relacionados con el agua y su gestión social”"12.

"Esta organización social, consta entre otras cosas de técnicas e ideologías relacionadas con el trabajo comunitario, que tienen un papel clave en la reproducción del nativo, de su identidad y su cultura. Es decir, de representaciones que explican las relaciones básicas entre los hombres, naturaleza (agua) y cosmovisión (autogobierno)" ${ }^{\prime 13}$.

Por tal motivo, Palerm, delimita el instrumento básico de trabajo y lo señala como "región", el cual es el punto de partida para la acción planificadora del desarrollo, sin ella no se puede entender ninguna acción concreta que, según se espera, tenga un resultado positivo. Del diagnóstico pasa a la estrategia y de ella se desprende el plan regional, recalcando fuertemente que éste siempre debe estar articulado con la nación, que es la que debe orientar la armonía, dirección o especialidad que debe tomar la región ${ }^{14}$.

Consecuentemente, el trabajo de campo de la región de la presa Huapango se realizó mediante el método etnográfico descrito en el segundo párrafo de este apartado. Se inició en marzo del 2013, con el recorrido de un transecto sur-norte; con observación y obtención de datos, socioambientales (identificación de actores y su relación con la presa). Dicho transecto se dividió en

\footnotetext{
10 Malinowsky, 1976.

11 Atkinson, 2001

12 Harris, 2001.

${ }^{13}$ Harris, 2001.

${ }^{14}$ Palerm, 1972. Romero et al, 2012.
} 
recorridos que permitieron la obtención de datos importantes en la cuenca hidrosocial de la presa Huapango para detectar los actores clave que dieron la información de la investigación.

Los datos generados en contacto directo con el objeto de estudio y los actores involucrados como fuentes directas de información, se complementaron con fuentes escritas de primera mano, como los archivos históricos locales y el trabajo de gabinete que consistió en la búsqueda de información en internet y las bibliotecas especializadas.

Dicho recorrido en la zona de estudio, permitió delimitar la cuenca socio territorialmente como una región con estructuras sociales propias, donde el uso del concepto de cuenca hidrosocial, permitió identificar las relaciones que hay entre los municipios que integran la presa Huapango, creando redes en torno al agua, así como entre sus actores de las zonas altas y zonas bajas (redes hídricas), mediante procesos de desarrollo hídrico (iniciativas locales, intervenciones), con historias particulares que configuran la cuenca hidrosocial.

Para la selección de los grupos de actores históricos en el trabajo de campo, se optó por la estrategia metodológica de trabajar con grupos ya establecidos e identificados históricamente, ya que "estas estructuras sociales son medios poderosos de participación en las acciones de planeación” ${ }^{15}$, por lo que esta táctica permitió la entrevista y el trabajo participativo de la mayoría de los actores de la cuenca hidrosocial, debido a su existencia previa y a su misma estructura histórica. En este sentido, el trabajo de campo jugó un papel fundamental en la investigación, ya que, para lograr el cometido, se tuvo que obtener información de primera mano en las comunidades de los municipios que integran la cuenca hidrosocial presa Huapango.

\section{RESUltados}

\section{Cuerpos de agua compartidos a nivel mundial}

Se detectaron en África, Europa, América Latina y México algunos cuerpos de agua compartidos que han hecho trabajo conjunto para atender problemáticas comunes, pero que merecen ser estudiados desde un enfoque de gestión integrada del agua y de gobernanza para obtener mayores resultados, ya que sus diversas situaciones deben ser atendidas desde un enfoque integral que considere los aspectos sociales, políticos, ambientales y económicos considerando las estructuras sociopolíticas que se han construido a través de la historia para tener el éxito esperado, como se sugiere para el caso de la Cuenca Hidrosocial Presa Huapango, ya que el trabajo conjunto de los cuerpos compartidos a nivel mundial se ha enfocado sólo en los siguientes aspectos:

- Cuerpos de agua compartidos en África

En el proyecto de ordenación ambiental del lago Victoria, se detectó lo siguiente:

1. Trabajo conjunto de los tres Estados litorales: Kenya, Tanzanía y Uganda.

2. El objetivo primordial fue la rehabilitación del ecosistema lacustre.

3. La primera fase de este proyecto comenzó en 1989, con el objetivo de alentar la

\footnotetext{
${ }^{15}$ Uphoff, 1988, 1995, 1999. Cernea, 1995. Bonnal, 1996.
}

cooperación en las cuestiones pesqueras entre los países lacustres. La segunda fase inició en 1995 para ayudar a establecer un marco de ordenación, un reglamento, para las pesquerías y crear una base de conocimientos para dicho marco.

4. Desarrollo de procesos participativos mediante la evaluación de estructuras comunitarias $^{16}$.

La falta de cooperación y regulación del uso del agua entre los países de la cuenca del Lago Chad (Chad, Camerún, Níger y Nigeria), dio por resultado el deterioro ambiental y la destrucción progresiva del potencial de producción del lago. La pesca en exceso se ha institucionalizado, y la mala planificación de los proyectos de irrigación ha contribuido también a la crisis. No se ha implementado un trabajo GIRH, sólo acciones aisladas por país ${ }^{17}$.

- Cuerpos de agua compartidos en Europa

En el convenio sobre la protección del río Rhin se detecta lo siguiente:

1. Creación de la Comisión Internacional para la Protección del río Rhin (CIPR); está compuesta por representantes de los Estados signatarios (Austria, Bélgica, Francia, Alemania, Italia, Liechtenstein, Luxemburgo, Países Bajos, Suiza). Su presidencia la ocupan por turnos dichos países. Toman las decisiones por unanimidad.

2. Tiene como objetivo proteger y mejorar el ecosistema del río.

3. Pretende consolidar la cooperación entre la comunidad y los estados ribereños del río mediante un reglamento que ordene el uso y protección del agua ${ }^{18}$.

- Cuerpos de agua compartidos en América

En Colombia se han venido implementando diferentes trabajos sobre el manejo de recursos comunitarios y cooperación; dentro de los cuales está el análisis de la acción colectiva en la laguna de Fúquene, donde se detectó lo siguiente:

1. Implementación de la propuesta metodológica en campo: participaron 160 personas entre agricultores, ganaderos y usuarios provenientes de los municipios que comparten la laguna.

2. Los participantes aportaron elementos para entender la percepción de los diferentes actores de la laguna y poder elaborar un reglamento de uso de ésta.

3. En campo pudo corroborarse la utilidad del análisis de la acción colectiva en el manejo de los recursos de uso común mediante la participación de la comunidad de la parte alta, media y baja de la cuenca de la laguna de Fúquene $^{19}$.

\footnotetext{
${ }^{16}$ FAO, 2004

${ }^{17}$ FAO, 2004.

${ }^{18}$ Unión Europea, 2006

19 Maya et al., 2004.
} 
- Cuerpos de agua compartidos en México

En la cuenca del lago de Pátzcuaro existe un estudio de gestión ambiental, donde se detecta lo siguiente:

1. Trabajo conjunto de los presidentes municipales que comparten el lago.

2. Integración de un Comité Ejecutivo Intermunicipal (CEIM) para hacer un reglamento.

3. Formación de equipos técnicos en los ayuntamientos.

4. Acciones conjuntas a partir del conocimiento de la problemática regional ${ }^{20}$.

Otro caso es el de la alianza de la cuenca del río Ayuquila, en Jalisco, que se creó para salvaguardar el río. Dicha alianza ha sido muy exitosa al integrar a la sociedad civil en esta tarea. Además de proteger el río, la alianza busca crear un ordenamiento territorial de la zona, tratar el agua, separar y manejar mejor los residuos sólidos y prevenir incendios en la Sierra de Manantlán.

El éxito de dicha alianza también inspiró la creación de la cooperación de los municipios costeros de Yucatán que busca proteger y crear un ordenamiento territorial de la costa en cuestión. La alianza obtiene el apoyo de prácticamente todas las instituciones académicas de la zona y fondos de fuentes internacionales como el Banco Mundial y las Naciones Unidas ${ }^{21}$.

Todos estos casos de cuerpos de agua compartidos dejan ver la necesidad de resolver problemáticas comunes a través de la GIRH y de la gobernanza como se sugiere en el siguiente estudio de la Cuenca Hidrosocial Presa Huapango, México.

La presa Huapango en México: un análisis de gestión integrada de los recursos hídricos y de gobernanza en un cuerpo de agua compartido

- Contexto y problemática de la presa Huapango

"En México se identificaron más de 4.462 presas; 667 de ellas están consideradas como grandes, por su capacidad de almacenamiento” ${ }^{22}$, pero “destacan 100 como más importantes en el país, dentro de éstas últimas se encuentra la presa Huapango para el caso del Estado de México” ${ }^{23}$, "ya que dicha presa es la más grande en extensión de dicho Estado, cuenta con una longitud de aproximadamente $22 \mathrm{~km}$ y un ancho de 3,5 km y la parte más angosta oscila entre 70 y 120 m de longitud, su cortina es de $110^{24}$ por su longitud es compartida por cinco municipios: Acambay, Aculco, Jilotepec, Polotitlán y Timilpan ${ }^{25}$.

La presa Huapango data de la época novohispana y su construcción fue financiada con los fondos de los religiosos y realizada aproximadamente durante los años de 1785-1788 en el antiguo lago de la sábana de Huapango ${ }^{26}$. Además, "tiene una capacidad de 121.300 millones de $\mathrm{m}^{3}$ y un almacenamiento de 37.859 millones de $\mathrm{m}^{3}$, se encuentra dentro de la cuenca del río Pánuco, que es una de las regiones hidrográficas más importantes del país, situada en cuarto lugar en la República Mexicana” 27.

La presa Huapango está situada en la región centro de México por lo que a través de la historia los pobladores han tenido que luchar contra los avatares que le conciernen a esta región porque el impacto combinado de la crisis del modelo de industrialización sustitutiva de importaciones, de las políticas de apertura y liberación comercial que le sucedieron y del nuevo “orden” global configurado por la creciente movilidad nacional e internacional del capital y del trabajo, así como de los avances tecnológicos en el campo de las telecomunicaciones, los transportes y los procesos de producción, han propiciado un nuevo patrón de expansión y crecimiento de las grandes aglomeraciones urbanas ${ }^{28}$.

A la luz de estas transformaciones, y considerando que uno de los rasgos más sobresalientes de la expansión actual de las grandes ciudades es la tendencia a conformar regiones nucleares (core regions) que comprenden a sus zonas metropolitanas y a otras metrópolis de menor tamaño, de los que Sau Paulo, Ciudad de México y Buenos Aires son los mejores ejemplos en América Latina $^{29}$.

Por lo que la presa Huapango está dentro del núcleo urbano industrial en México, ya que éste está conformado por la Ciudad de México y el Estado de México, que son las entidades sobre las que se ha extendido la zona metropolitana de la ciudad de México. A su vez la periferia regional comprende a los estados circundantes de Puebla, Morelos, Querétaro, Hidalgo y Tlaxcala, cuyo dinamismo económico y migratorio está notoriamente influenciado por el comportamiento del núcleo. En este sentido, cabe señalar que la presa Huapango está en los límites de los Estados de México, Querétaro e Hidalgo y muy cerca de la Ciudad de México, lo que la hace aún más vulnerable porque son Estados en constante crecimiento y con una demanda de agua cada vez mayor para consumo humano y uso industrial ${ }^{30}$.

Por ejemplo, proveer los miles de millones de litros que requiere la Ciudad de México -situada a 2.400 metros por encima del nivel del mar- es una de las grandes hazañas mundiales de ingeniería hidráulica, ya que a pesar de que la Ciudad de México tiene más días lluviosos que Londres, sufre de una escasez hídrica comparable con la de un desierto, lo que hace que el precio de cada litro de

\footnotetext{
${ }^{20}$ Lazos, 2006.

21 Instituto Mexicano para la Competitividad, 2014.

22 Conagua, 2009.

23 INEGI, 2010.

${ }^{24}$ H. Ayuntamiento de Aculco, 2009. Inafed, 2013.

25 García, 2013.
}

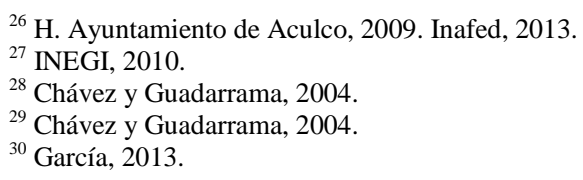


agua sea de los más elevados del mundo, a pesar de que su calidad a menudo sea baja ${ }^{31}$.

Los crecientes costos -sociales, económicos, sanitarios y medioambientales- son una fuente de estrés y conflicto. Los líderes políticos y las grandes corporaciones impulsan proyectos de ingeniería hidráulica aún más voluminosos, que son rechazados por los por grupos indígenas. El Congreso y las ONGs se enfrentan en cuanto a la posible privatización del agua. Entretanto, la escasez hídrica crea tensiones sociales en la Ciudad de México y en los estados aledaños.

Es por ello, que, a nivel mundial, el agua es más valiosa, y se le pone mayor atención, que nunca antes. Jamás ha existido una mayor necesidad por encontrar nuevas formas de abordar el problema. Existen pocos lugares que demuestren lo anterior con mayor claridad que la Ciudad de México, donde este vital elemento corre por un sistema que cada día se vuelve más largo, complejo y rebasado. Desde su fuente original hasta llegar al desagüe, la trayectoria de cada gota expresa una historia heroica, trágica, inacabada, de crecimiento urbano y desarrollo humano ${ }^{32}$.

Consecuentemente, la presa Huapango se encuentra inmersa dentro de una problemática regional con impacto global que le ha permitido existir gracias a las estructuras sociales de sus pobladores consolidadas a través de la historia, por lo que la sustentabilidad de dicho cuerpo de agua sólo podrá lograrse mediante acuerdos institucionales de cooperación regional entre sus pobladores a través de la GIRH y la gobernanza. Por tal motivo, para este análisis se optó por la percepción de la problemática desde el punto de vista de los pobladores de la región y de algunos trabajos que anteceden a esta investigación, donde se detectaron una serie de problemas ambientales, sociales, económicos y políticos en dicho cuerpo de agua:

\section{a) Problemas ambientales}

Se detectan cuatro descargas de aguas residuales en el embalse Huapango, siendo la más perjudicial la ubicada en la comunidad de Zaragoza, allí se recolecta el $100 \%$ de la descarga de comunidades aledañas para tratarse, sin embargo, la planta de tratamiento no se encuentra operando y las descargas las vierten al embalse sin un tratamiento previo. Se identifica que en los lugares donde existe el servicio de drenaje, las descargas son vertidas en los ríos que desembocan en las presas de Cofradía, el Molino, San Antonio y Huapango. Los ríos y arroyos son los conductores de la mayor parte de los desagües de las comunidades. También hacia el sur en la Isla de las Aves y la presa del Ocotal desembocan aguas negras. El volumen de descargas es en promedio 150 lts/persona/día ${ }^{33}$. La tala actual

\footnotetext{
${ }^{31}$ Watts, 2015.

32 Watts, 2015.

${ }^{33}$ H. Ayuntamiento de Timilpan, 2009.
}

de los bosques que circundan la subcuenca de la presa, está provocando erosión y azolve en el cuerpo de agua. Se ha detectado un proceso de disminución de especies nativas en la presa: ajolote (Ambystoma granulosum), charal (Girardinichthys multiradiatus), acocil (Cambarellus montezumae), rana y renacuajo (Pelophylax); además se han reintroducido nuevas especies que están deteriorando el cuerpo de agua: lirio acuático y carpa. Los agostaderos en las orillas de la laguna para el ganado se encuentran en franco agotamiento por sobrepastoreo, principalmente en la orilla de la presa. A esto se suma la contaminación por ruido de la autopista Arco Norte ${ }^{34}$.

b) Problemas sociales

Existe extracción sin límites fijos de peces por parte de los pescadores y población ribereña, invadiendo y traspasando los límites municipales en la presa; también existe una libre extracción de agua ligada al aumento per cápita para los animales y la agricultura; el abatimiento de los recursos naturales ligados al agua, se sospecha que ha provocado emigración de la población. Finalmente, esta pérdida natural se traduce en un deterioro de la alimentación tradicional lacustre y sus consecuencias en la población directamente beneficiada de la presa, además se empiezan a tener problemas de salud en la zona aledaña a la presa por la inserción de contaminantes al cuerpo de agua ${ }^{35}$.

\section{c) Problemas económicos}

Los municipios reportan cambios de uso de suelo ribereño a habitacional; existen fugas de agua en la cortina de la presa por falta de mantenimiento (en Aculco), lo cual abate el nivel de la presa más rápidamente; hay un deterioro económico de la agricultura con riego por la homologación de los precios con los internacionales; la sobrepesca ha elevado los precios de las especies nativas capturadas; falta organización del potencial turístico de la zona; se reporta abigeato entre municipios; hay una distribución inequitativa del agua entre municipios, Aculco y Polotitlán que acaparan el mayor gasto de agua para el ganado (riego de alfalfa y agua para los animales), lo que provoca conflictos con Acambay, Jilotepec y Timilpan $^{36}$.

\section{d) Problemas políticos}

Se detectan problemas intermunicipales sobre los límites de la presa; hay conflicto por el aprovechamiento pesquero del embalse y en la regulación de los niveles del agua, ya que las fluctuaciones por el riego y para el ganado, reducen la actividad en aquellas zonas donde los niveles bajan considerablemente; la pesca se

\footnotetext{
34 CAEM, 2002. H. Ayuntamiento de Timilpan, 2009. H. Ayuntamiento de Aculco, 2009. Estrada et al., 2011. García, 2013.

35 INEGI, 2010. García, 2013.

${ }^{36}$ CAEM, 2002. H. Ayuntamiento de Timilpan, 2009. García, 2013.
} 
ve disminuida o interrumpida cuando la CONAGUA requiere bajar el nivel de la presa, por una falta de control en el vertedero del embalse; existe inconformidad de los municipios que no usan el agua intensivamente para riego, pero que la presa ocupa una buena parte territorial de sus ejidos ${ }^{37}$.

De igual forma, la Comisión del Agua del Estado de México (CAEM), en un estudio estatal sobre los principales cuerpos de agua y su calidad, identificó que la presa Huapango:

1. Tiene graves problemas de contaminación por falta de tratamiento de las aguas residuales.

2. Alto crecimiento demográfico en sus alrededores, sobre todo en la ribera del lago.

3. Aumento del consumo per cápita del agua.

4. Fugas por más del $30 \%$ por falta de mantenimiento de la infraestructura.

5. Tala inmoderada de bosques en la subcuenca alta.

6. Erosión de los suelos y arrastre de sedimentos.

7. Cambios ambientales y sus efectos sobre el régimen de lluvias ${ }^{38}$.

En el mismo sentido, en un estudio sobre daños colaterales de las carreteras identificaron que "La construcción del puente de la Autopista Arco Norte $^{39}$ dentro de la presa Huapango ha traído cambios dramáticos en el entorno (ruido, usos del suelo, perturbación de los animales nativos, descenso de áreas de cultivo y pastoreo)”“40.

Dichas problemáticas han dañado la $\mathrm{CHPH}$, por lo que sólo a través de la GIRH y de la gobernanza los pobladores podrán revertir los daños, ya que desde antaño se ha reconocido la importancia que tiene dicho cuerpo de agua para la región como lo señaló el antropólogo Román Piña Chan, desde 1976 cuando identificó a la presa Huapango como un cuerpo de agua compartido muy importante para la región norte del Estado de México en México, ya que describió que dicho cuerpo de agua tiene un potencial para el desarrollo de la población usuaria de la presa, ya que es posible el regadío y un ambiente favorable para la fauna lacustre (gallaretas, patos y gansos), la cual resultaba de vital importancia para la dieta de los huamangueros de tiempos pasados, recomendando su conservación al estado Mexicano ${ }^{41}$.

En un estudio sobre la pesca ribereña de la presa Huapango, detectaron que “...existen al

\footnotetext{
${ }^{37}$ García, 2013.

38 CAEM, 2002.

39 La Autopista Arco Norte es el libramiento más grande que hay en México, con 224 kilómetros. Conecta desde el Estado de Puebla, pasando por Tlaxcala, por Hidalgo, por el Estado de México; rodea toda la zona centro y metropolitana del Valle de México, permite evitar el paso de carga y hacer más ágil y más rápida la comunicación entre esta región del país con el occidente (Estrada, et al., 2011).

40 Estrada et al. 2011.

${ }^{41}$ Piña, 1976.
}

momento aproximadamente 137 pescadores activos y 63 eventuales. Los cuales tienen una dedicación especial a la pesca, lo que ha derivado en una tradición pesquera regional”42. La captura de pescado ha dado un valor agregado artesanal para la venta a vecinos y mercados locales, creando una cultura lacustre y cocina lacustre, por lo que se requiere sostener el cuerpo de agua que es compartido por gran parte de la región norte del Estado de México.

- Delimitación del área de estudio

En este apartado se describe la región de estudio y la construcción del sistema socio cultural (histórico, agrario, hídrico) de la región, para entender la conformación de los grupos sociales en la Cuenca Hidrosocial Presa Huapango, donde el ejido como estructura social de grupos, aparece con identidad y organización social histórica, lo cual permite identificar a grupos sociales para la GIRH y concibe la operatividad de los conceptos que permiten detectar una identidad e historia común a través de la gobernanza.

La región de estudio se delimitó mediante el concepto de cuenca hidrosocial que está principalmente orientado a:

* La definición clara del ámbito geográfico de influencia de la gestión y uso del agua en el ámbito de cuencas hidrográficas, considerando los trasvases de agua y las áreas de influencia inmediatas de la cuenca hidrográfica, no sólo en términos hídricos sino políticos y sociales.

* A partir de la definición de éste ámbito geográfico, así como de la visualización de las relaciones de (inter) dependencia (hídricas y sociales), entre usuarios de aguas arriba y aguas abajo, el concepto permite analizar las históricas relaciones hidrosociales, así como las proyecciones futuras y sus implicaciones sobre la gestión del agua, su disponibilidad y sus usos potenciales.

* Al estar incorporados en la "cuenca hidrosocial” los actores, sus espacios territoriales y jurisdiccionales, el concepto se convierte en una poderosa herramienta de análisis como de negociación, ya que permite visualizar más claramente los problemas críticos, sus causas y sus efectos, facilitando la toma de decisiones sobre determinadas acciones concretas.

* El concepto de cuenca hidrosocial permite generar una visión más integral del espacio en el cual se pretende planificar, intervenir, gestionar, investigar, etc. permite una priorización de las acciones estratégicas, los planes de acción a seguir, y ayuda a definir las responsabilidades, tareas y metas de los diversos actores, dando en conjunto mucha más coherencia a procesos de planificación, desarrollo y gestión de recursos hídricos ${ }^{43}$.

\footnotetext{
42 Gallego et al. 2012.

43 Quiroz, Delgadillo y Durán, 2012.
} 
Bajo estas premisas la cuenca hidrosocial es un concepto que espacialmente rebasa la cuenca hidrográfica $^{44}$, rebasa jurisdicciones político administrativas (departamento, provincia, municipio). Está más bien basado en las redes que se crean en torno al agua entre gente de las zonas altas y zonas bajas (redes hídricas) mediante procesos de desarrollo hídrico (iniciativas locales, intervenciones) con historias particulares que configuran esta cuenca hidrosocial, encontrando equilibrios temporales pero sujetos a situaciones de conflicto y resolución continuos, pudiéndose contraer o expandir en el tiempo ${ }^{45}$.

Por tal motivo, la cuenca hidrosocial es limitada tanto por los límites físicos (fuentes de agua, infraestructura de aprovechamiento, áreas de influencia de los sistemas, etc.) como sociales (acuerdos entre usuarios aguas arriba y usuarios aguas abajo).

Es por ello, que a partir de la definición de éste ámbito geográfico y de la visualización de las relaciones de (inter) dependencia (hídrica y social), entre usuarios de aguas arriba y aguas abajo, permite analizar las históricas relaciones hidrosociales, así como las proyecciones futuras y sus implicaciones sobre la gestión del agua, su disponibilidad y sus usos potenciales.

El concepto “cuenca hidrosocial” engloba tres términos: cuenca, hidro y social, por lo que bajo estas premisas, con el software IDRISI y con el trabajo de campo de García (2013), se delimitó el área de estudio: la Cuenca Hidrosocial Presa

Mapa 1. Localización del Estado de México y la Cuenca Hidrosocial Presa Huapango en México

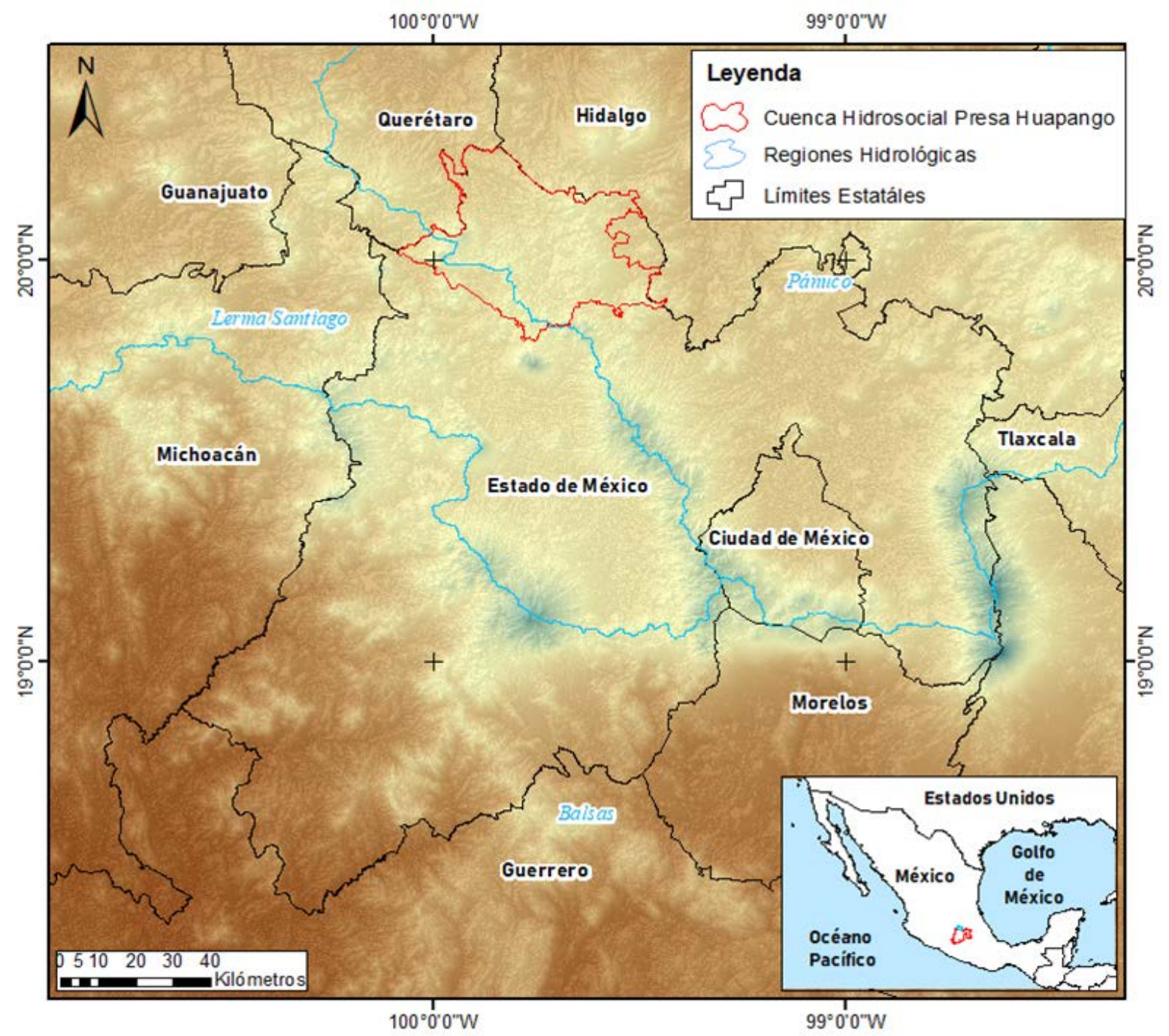

Fuente: Elaboración propia con base en el Trabajo de Campo, García (2013).

44 Cotler y Caire (2009: 16), definen a la cuenca hidrográfica como territorio de análisis y gestión. Por ser un territorio delimitado naturalmente por una divisoria de aguas, llamada "parteaguas", que determina que el agua que recorre todo el territorio confluya y desemboque en un punto común, ya sea un océano (cuenca exorreica) o un lago interno (cuenca endorreica). En este territorio, delimitado por límites naturales, sus paisajes constituyen la manifestación espacial de la relación entre las sociedades, rurales y urbanas y su ambiente.

45 Quiroz, Delgadillo y Durán, 2012: 114.
Huapango que contempla los actores de cinco municipios del Estado de México: Aculco, Polotitlán, Acambay, Jilotepec y Timilpan, donde existen redes entre pobladores de aguas abajo y aguas arriba, ya que los dos primeros municipios se encuentran aguas abajo y los tres restantes aguas arriba como se muestra en el mapa de la Cuenca Hidrosocial Presa Huapango (Ver Mapa 1). 
La Cuenca Hidrosocial Presa Huapango, México: Un análisis de la Gestión Integrada de los Recursos Hídricos y la gobernanza en cuerpos de agua compartidos

Cabe señalar que la Cuenca Hidrosocial Presa Huapango está ubicada al norte del Estado de México en las Regiones Hidrológicas del Pánuco y Lerma Santiago y está colindando con los Estados de Querétaro e Hidalgo como se muestra en el Mapa 2.
1. Actores históricos (multiactores ${ }^{46}$ : pescadores, agricultores y ganaderos), dentro de los cuales se encuentran las autoridades auxiliares (Delegados Municipales y Comisariados Ejidales).

Mapa 2. La Cuenca Hidrosocial Presa Huapango

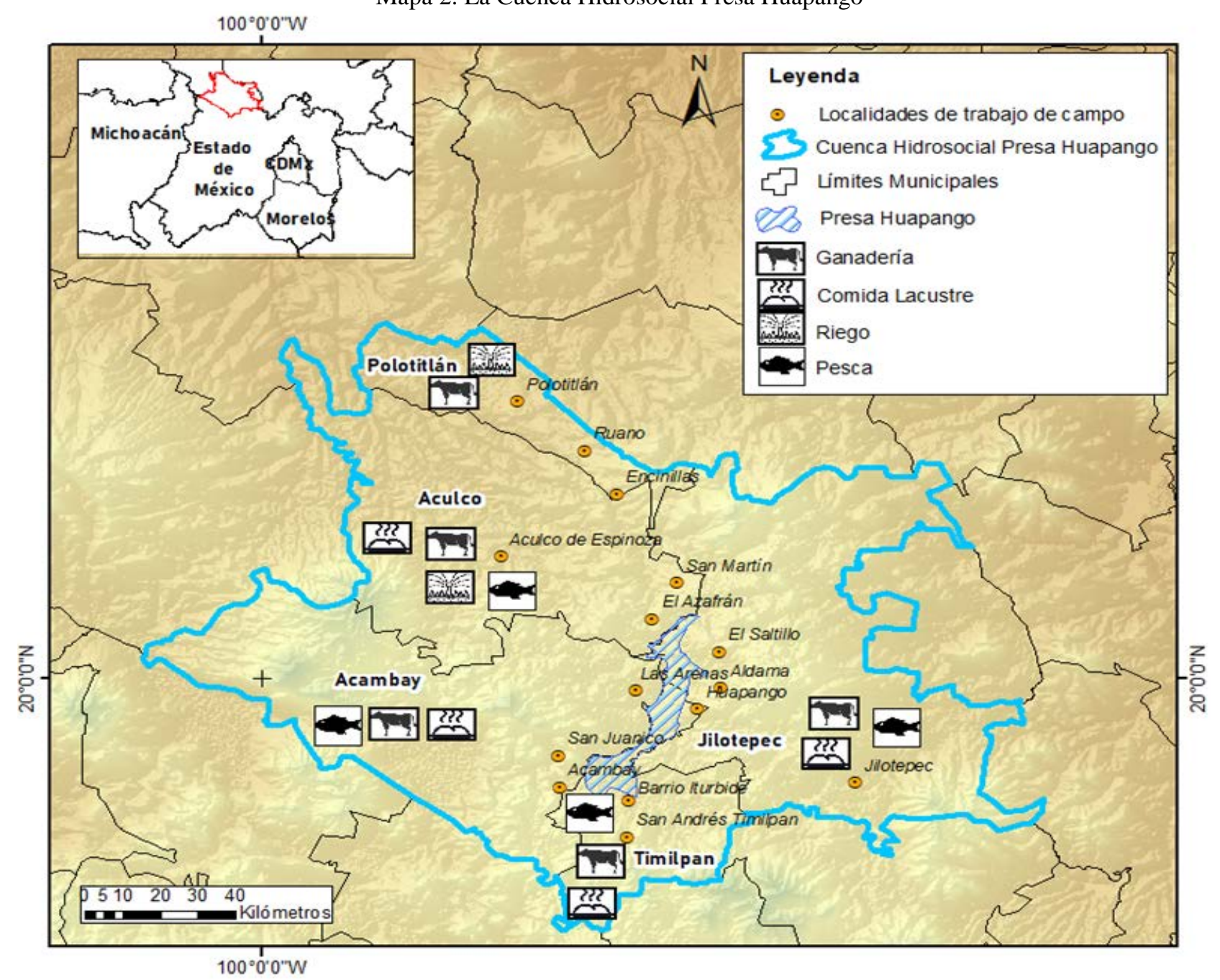

Fuente: Elaboración propia con base en el Trabajo de Campo, García, 2013.

Una vez delimitada el área de estudio se procedió a la identificación de localidades y actores en la $\mathrm{CHPH}$, obteniendo los siguientes resultados.

- Identificación de localidades y actores en la $\mathrm{CHPH}$

Las localidades que fueron identificadas y elegidas para el trabajo de campo, como se aprecia en la Tabla 1, son las que articulan fundamentalmente el espacio geográfico de la cuenca hidrosocial de la presa Huapango, ya que existen allí más grupos de actores en términos de presencia actual y que guardan las estructuras sociales a través de la historia, las cuales permitieron identificar las relaciones de GIRH y de gobernanza.

En estas localidades y municipios se realizaron 77 entrevistas abiertas y directas a grupos de actores identificados mediante la metodología de grupos ya establecidos, donde se identificaron tres grupos:
2. Actores del gobierno municipal (Presidentes Municipales y Regidores Presidentes de las Comisiones de Medio Ambiente y Recursos Naturales (agua), así como los Directores de Medio Ambiente y Ecología).

3. Actores del gobierno federal (Funcionarios de la Comisión Nacional del Agua (Conagua) del Distrito de Riego 096 y la Asociación de Usuarios del Sistema de Riego Huapango Arroyo Zarco México S.A.), por lo que el número de entrevistados por grupo se señala en la Tabla 2. 
Tabla 1. Localidades donde se llevó acabo el trabajo de campo

\begin{tabular}{|c|c|c|}
\hline & Municipio & Localidad \\
\hline \multirow{9}{*}{ 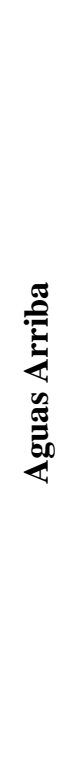 } & \multirow{3}{*}{ Acambay } & Acambay \\
\hline & & Las Arenas \\
\hline & & San Juanico \\
\hline & \multirow{3}{*}{ Jilotepec } & Jilotepec \\
\hline & & Aldama \\
\hline & & El Saltillo \\
\hline & \multirow{3}{*}{ Timilpan } & San Andrés Timilpan \\
\hline & & Huapango \\
\hline & & Barrio Iturbide (La Campesina) \\
\hline \multirow{6}{*}{ 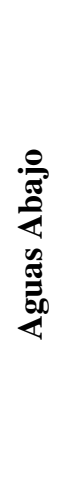 } & \multirow{3}{*}{ Aculco } & Aculco \\
\hline & & San Martín \\
\hline & & El Azafrán \\
\hline & \multirow{3}{*}{ Polotitlán } & Polotitlán \\
\hline & & Ruano \\
\hline & & Encinillas \\
\hline
\end{tabular}
2013.

Tabla 2. Número de entrevistas realizadas en trabajo de campo

\begin{tabular}{|c|c|}
\hline \multicolumn{2}{|c|}{$\begin{array}{c}\text { ACTORES HISTÓRICOS } \\
\text { (Multiactores) }\end{array}$} \\
\hline $\begin{array}{c}\text { Pescadores, Ganaderos, Industria } \\
\text { Láctea, Turismo }\end{array}$ & 25 \\
\hline $\begin{array}{c}\text { Autoridades Auxiliares (Comisariados } \\
\text { Ejidales y Delegados Municipales) }\end{array}$ & 22 \\
\hline Total & $\mathbf{4 7}$ \\
\hline ACTORES GUBERNAMENTALES \\
\hline Municipales & 27 \\
\hline Federales & 3 \\
\hline Total & $\mathbf{3 0}$ \\
\hline TOTAL GENERAL & $\mathbf{7 7}$ \\
\hline
\end{tabular}

Fuente: Elaboración propia con base en el trabajo de campo, García, 2013.
La realización de dichas entrevistas permitió tener la información clave para realizar la propuesta de GIRH y gobernanza en el cuerpo de agua compartido como veremos en el siguiente apartado.

- Información obtenida en las 77 entrevistas realizadas a los grupos de actores ya establecido en la $\mathrm{CHPH}$

1. Se identificaron cinco mapas de actores de la CHPH conformados de la siguiente forma

En el Esquema1, Mapa de Actores Históricos, El Ejido se identifica como el mecanismo institucional con mayores relaciones con la Cuenca Hidrosocial Presa Huapango y con mayores redes sociales.

Los ejidatarios de la cuenca hidrosocial fueron dotados de tierra cuando se fraccionó la Hacienda Arroyo Zarco a partir de 1920 (municipio de Aculco); ellos tienen múltiples trabajos o funciones: agricultores, ganaderos, pescadores, comerciantes, turismo e industria láctea en pequeña escala. La máxima autoridad dentro de El Ejido es la Asamblea General, que agrupa principalmente a los agricultores donde los ejidatarios están facultados por la ley para asociarse en cooperativas o asociaciones que compartan una misma actividad o un mismo interés.

En el Esquema 2, Mapa de Actores Municipales de Agua y Medio Ambiente, se pudo detectar que los cabildos y jefes de medio ambiente que tienen a su cargo el tema del agua, tienen poca o nula identidad con la cuenca hidrosocial y con los actores de dicha cuenca, ya que proceden de otros municipios y porque el periodo de gobierno municipal sólo dura tres años, lo que es poco tiempo para entender, detectar $\mathrm{y}$ resolver los problemas de la cuenca.

Cuando se constituyen los Ejidos y los Municipios como instituciones, surgen las autoridades auxiliares, que en contraste con el anterior mapa de actores municipales, donde existe una estructura orgánica diferente para cada uno de los municipios, se detectó una misma estructura integrada por delegados municipales (representantes del ayuntamiento) y comisariados ejidales (representantes de El Ejido) y sólo para el caso del municipio de Timilpan un presidente de unión de ejidos (representante de todos los ejidos del municipio).

Los delegados son representantes del Ayuntamiento y vínculo con la ciudadanía en el territorio municipal, además de constituirse en gestores de servicios para sus respectivas localidades. El cargo de delegado se designa mediante procedimientos de elección directa o indirecta a propuesta del Ayuntamiento en asambleas vecinales o por aplicación de procedimientos electorales que organiza la 


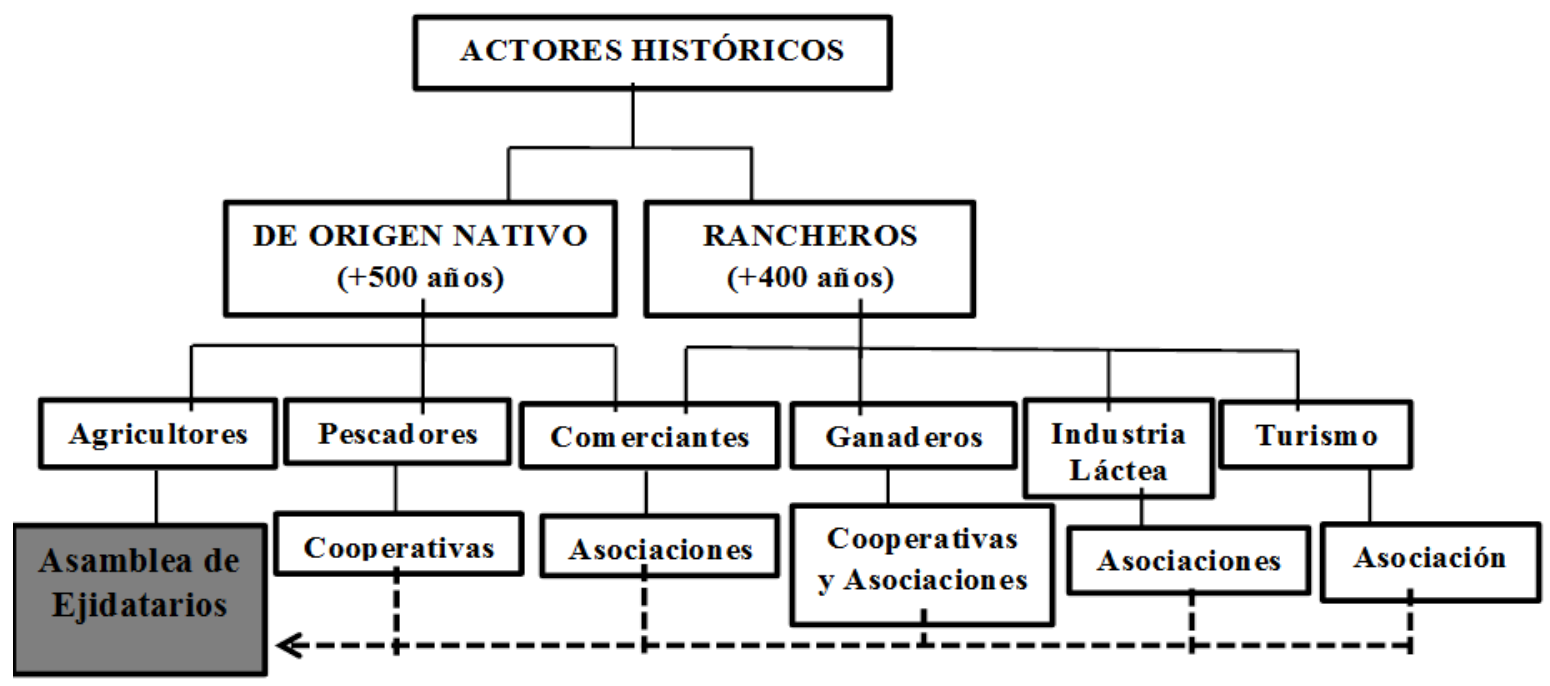

Fuente: Elaboración propia con base en el Trabajo de Campo, García, 2013.

Esquema 2. Mapa de Actores Municipales de Agua y Medio Ambiente

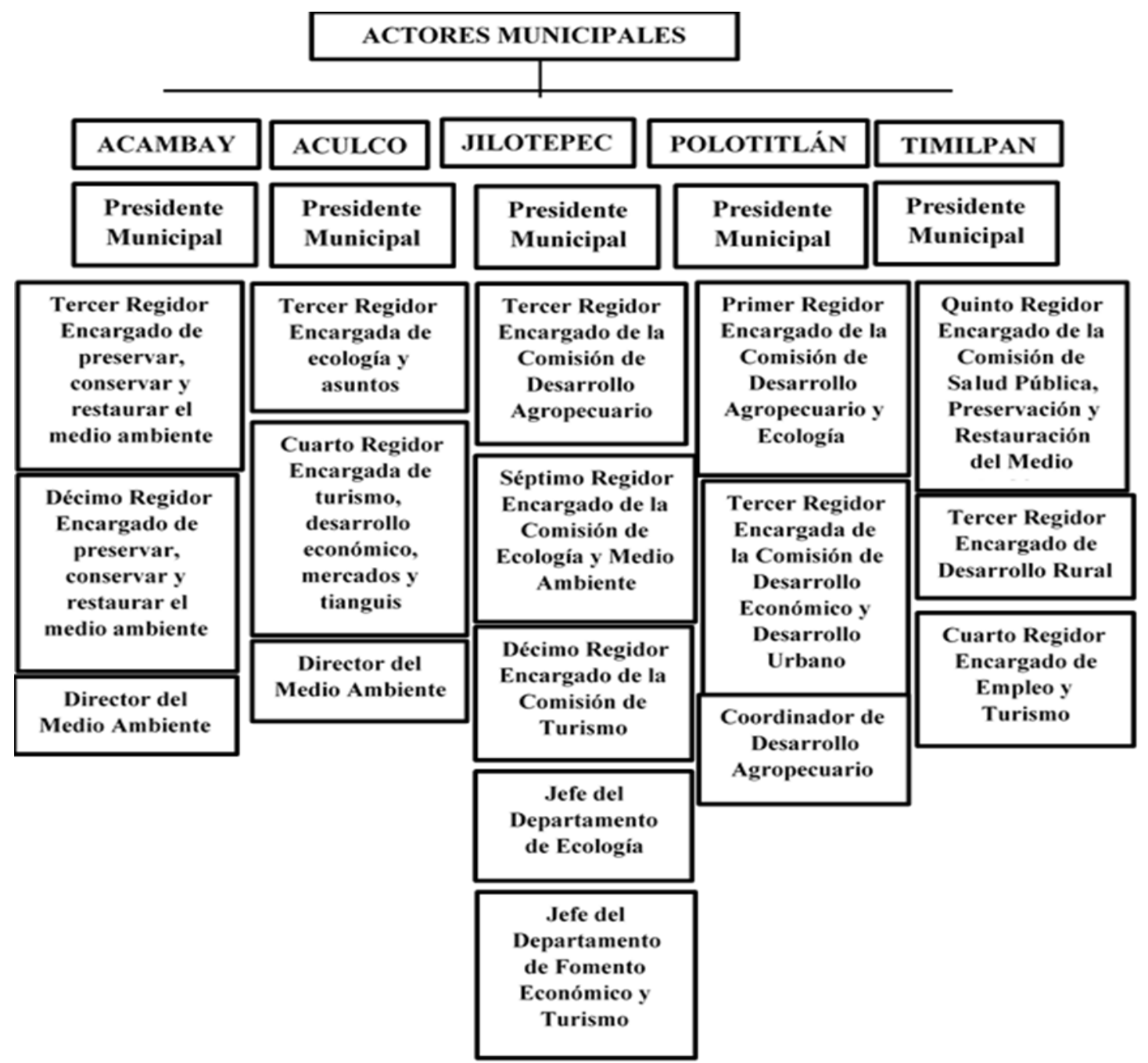

Fuente: Elaboración propia con base en la revisión bibliográfica y el Trabajo de Campo, García, 2013. 
propia autoridad municipal y tienen una duración de tres años, periodo que coincide con la duración del Ayuntamiento. Son ciudadanos que las comunidades eligen y son reconocidos oficialmente por el Ayuntamiento. No tienen facultades ejecutivas, pero tienen a su cargo funciones auxiliares de seguridad pública; organizan a la comunidad para la prestación de servicios públicos; se desempeñan como auxiliares de recaudación de contribuciones especiales; representan a la comunidad ante el ayuntamiento; tienen a su cargo la expedición de constancias de residencia, entre otras.

En el Esquema 3, Mapa de Actores de las Autoridades Auxiliares, se identifica que existen para todos los municipios las figuras de delegados municipales y comisariados ejidales. Estos actores representan el contacto directo entre los tres niveles de gobierno y la sociedad. Se aprecia por su origen, que estos actores guardan una gran identidad regional que comparten con los otros actores de la cuenca, entendido esto como una estructura social de origen antiguo.

En el Esquema 4, Mapa de Actores Estatales, se aprecian los actores de gobierno estatal y su relación con la cuenca hidrosocial presa Huapango. Dicha relación está expresada a través de tres Secretarías: Secretaría de Medio Ambiente, Secretaría del Agua y Obra Pública, y la secretaría de Desarrollo Agropecuario. Destaca la última por la vocación agrícola y ganadera que tiene la región.

En el Esquema 5, Mapa Mental de Actores Federales, se identifican los principales actores federales en la cuenca hidrosocial presa Huapango que están dadas por tres Secretarías de Estado: 1. la Secretaría de Medio Ambiente y Recursos Naturales (Semarnat); 2. la Secretaría de Agricultura, Ganadería, Desarrollo Rural, Pesca y Alimentación (Sagarpa) y 3. la Secretaría de Desarrollo Agrario, Territorial y Urbano (Sedatu), así como con la Cámara de Diputados Federal y los Tribunales Agrarios.

En el Esquema 5, Mapa Mental de Actores Federales, se identifican una amplia gama de relaciones de los actores de la cuenca hidrosocial presa Huapango con las tres secretarías de Estado (Semarnat, Sagarpa y Sedatu) y con los Tribunales Agrarios, ya que es una zona constituida en núcleos agrarios a través de los Ejidos. Destaca la relación con la primera Secretaría, Semarnat, que está dada mediante la Comisión Nacional del Agua (Conagua) a través del Distrito de Riego 096 y la Asociación de Usuarios de Riego.

\section{Redes y funciones de los actores}

Se identificaron las redes y funciones de todos los grupos de actores, donde destacan los ejidatarios como eje central de la interrelación social con los otros actores.

Con base en el Esquema 6, Redes, y funciones de todos los actores, se pudo identificar que los que tienen mayores relaciones en la Cuenca Hidrosocial Presa Huapango son los ejidatarios, que a través de las autoridades auxiliares (delegados municipales y comisariados ejidales) que son electos cada tres años se encuentran representados y se interrelacionan con otros actores: históricos, actores municipales, actores estatales y federales, por lo que fungen como el principal enlace de gestión entre todos los actores para presentar sus demandas sociales ante distintas dependencias gubernamentales y para solucionar los problemas en comunidad.

Cabe señalar que la región de la cuenca hidrosocial presa Huapango es netamente ejidal, donde la figura del Ejidatario es sin duda la más importante, ya que el Ejidatario es un actor que posee la tenencia de la tierra desde antiguo, y que junto con ella ha adquirido una serie de valores socioculturales que le permiten identificarse y pertenecer al grupo de actores históricos que por su identidad y compromiso social, poseen la representación más amplia de la cuenca mediante la figura de autoridades auxiliares (Comisariado Ejidal y Delegado Municipal), lo cual les permite tener injerencia en la resolución de sus propios problemas, y mediante la autogestión de sus recursos les ha permitido relacionarse con otros actores de carácter gubernamental.

De igual forma destaca que los Ejidatarios tienen mayores vínculos con los actores del gobierno federal, más que con el estatal, ya que El Ejido es una institución creada por la federación y las instituciones que tienen que ver con éste dependen directamente del gobierno federal (la Sedatu, el RAN, la Procuraduría Agraria, los Tribunales Agrarios) por lo que cualquier trámite referente a El Ejido tiene que ser directamente en estas instituciones.

Por otro lado, los Ejidatarios, son actores que representan a la comunidad mediante la figura de Delegados Municipales, lo que hace que tengan contacto con las instituciones del gobierno municipal y estatal para gestionar recursos para su comunidad, es decir, los actores municipales y estatales también están presentes en la vida del ejidatario, aunque en muchas ocasiones no logran resolverles sus demandas. Aquí se detecta una falta u omisión de parte de estas dependencias en sus obligaciones, sin embargo, es posible 


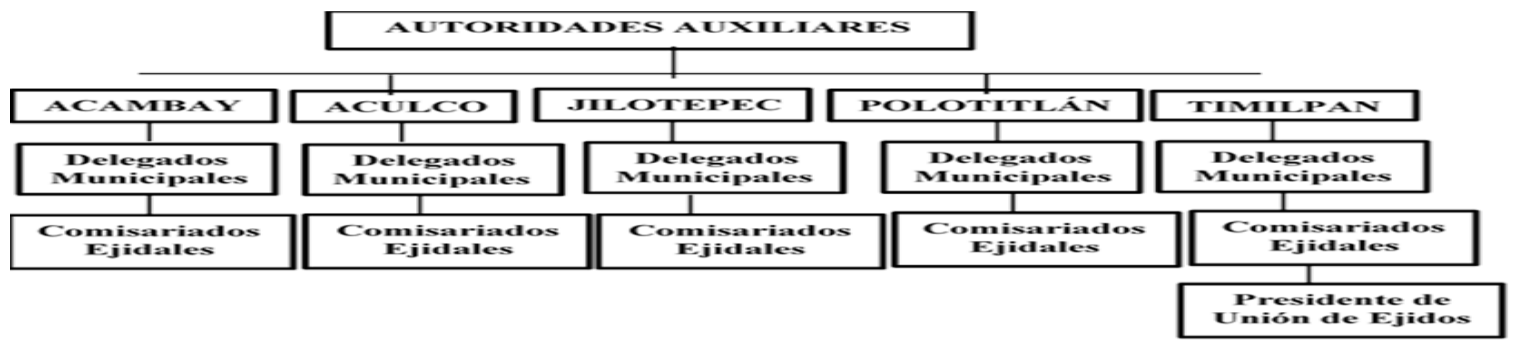

Fuente: Elaboración propia con base en el Trabajo de Campo, García, 2013.

Esquema 4. Mapa de Actores Estatales

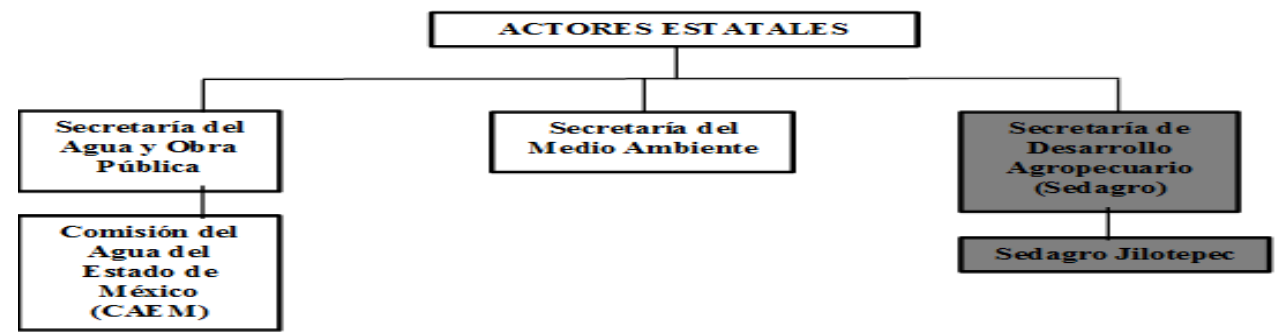

Fuente: Elaboración propia con base en la revisión bibliográfica y el Trabajo de Campo, García, 2013.

Esquema 5. Mapa Mental de Actores Federales

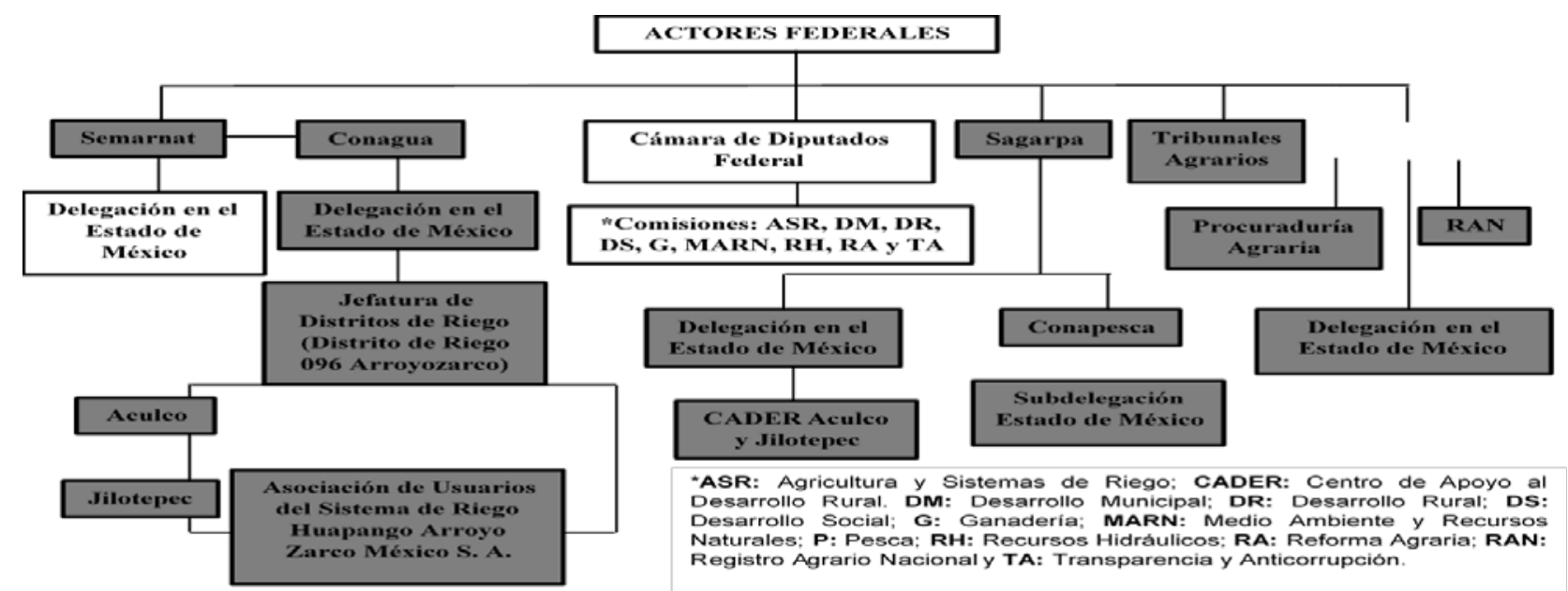

Fuente: Elaboración propia con base en la revisión bibliográfica y el Trabajo de Campo, García, 2013.

Esquema 6. Redes y funciones de actores

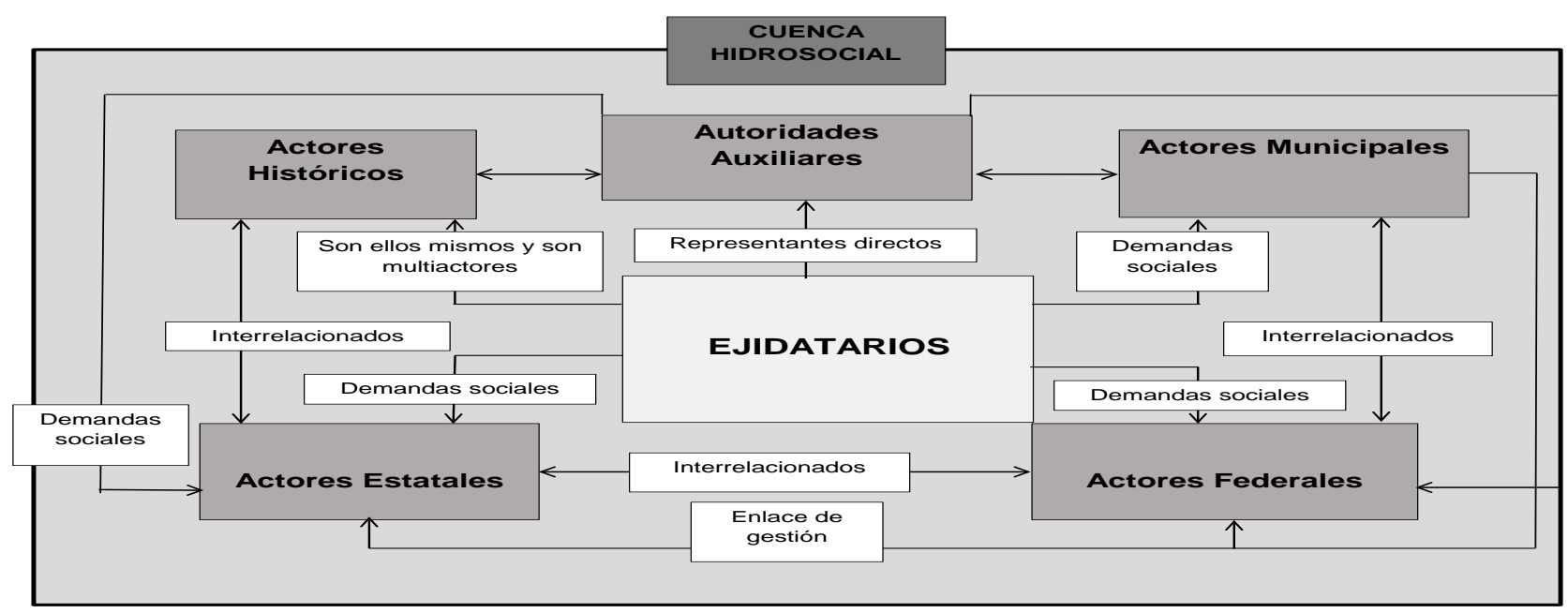

Fuente: Elaboración propia con base en la revisión bibliográfica y el Trabajo de Campo, García, 2013. 
que esto se deba a la histórica limitación que el municipio ha estado sujeto por parte del Estado Federal.

Por otro lado, destaca que el vínculo más importante entre todos los actores, es precisamente entre actores históricos, ya que sus redes $\mathrm{y}$ funciones se han consolidado a través de la historia y esto hace que tengan instituciones muy antiguas que han ayudado a solucionar problemas de gestión de toda índole. Fungen como institución social a la hora de resolver sus problemas comunitarios, por ejemplo, es recurrente la práctica de asociación entre el Delegado Municipal, el Comisariado Ejidal $\mathrm{y}$ entre otras autoridades locales, para atender problemáticas de interés general o común.

3. Principios de gobernanza

Se identificaron una serie de principios de gobernanza: Identidad, cultura, autogestión, poder, relaciones intermunicipales, gobernabilidad, cooperación, participación social, democracia y voluntariedad de la sociedad que permitieron estructurar la información del trabajo de campo para la elaboración de la propuesta que hicieron los actores en trabajo de campo de la creación de un Comité intermunicipal para el uso, cuidado y defensa de la presa Huapango con su Reglamento.

4. Propuesta de Comité intermunicipal para cuidar, defender y administrar los recursos naturales de la Cuenca Hidrosocial Presa Huapango con su Reglamento

El Comité Intermunicipal es una propuesta intermunicipal para la gestión integrada y la gobernanza de la Cuenca Hidrosocial Presa Huapango, dicha proposición se obtuvo en concordancia con las respuestas de las entrevistas que se hicieron a los actores históricos de la $\mathrm{CHPH}$ $\mathrm{y}$ a los actores del gobierno en trabajo de campo y está basado en las estructuras de usos y costumbres de los actores de la Cuenca, así como en la organización sociopolítica de las autoridades auxiliares de la región.

El Comité estará integrado por actores históricos, dado que en el transcurso de la investigación, se concluyó que son los actores que tienen mayor identidad, capacidad y responsabilidad, para manejar, cuidar y administrar los recursos naturales de la CHPH y evitar conflictos al respetar los usos y costumbres (derecho consuetudinario) que han adquirido a través de la historia, ya que el resto de los actores tienen establecidas sus funciones $y$ responsabilidades para con la Cuenca mediante la ley formal, por lo que estos últimos sólo fungirán en el Comité, como actores de apoyo con voz, pero sin voto en las asambleas.

El Esquema 7 muestra cómo estará integrado el Comité

Esquema 7. Comité Intermunicipal para Cuidar, Defender y Administrar los Recursos Naturales de la Cuenca Hidrosocial Presa Huapango.

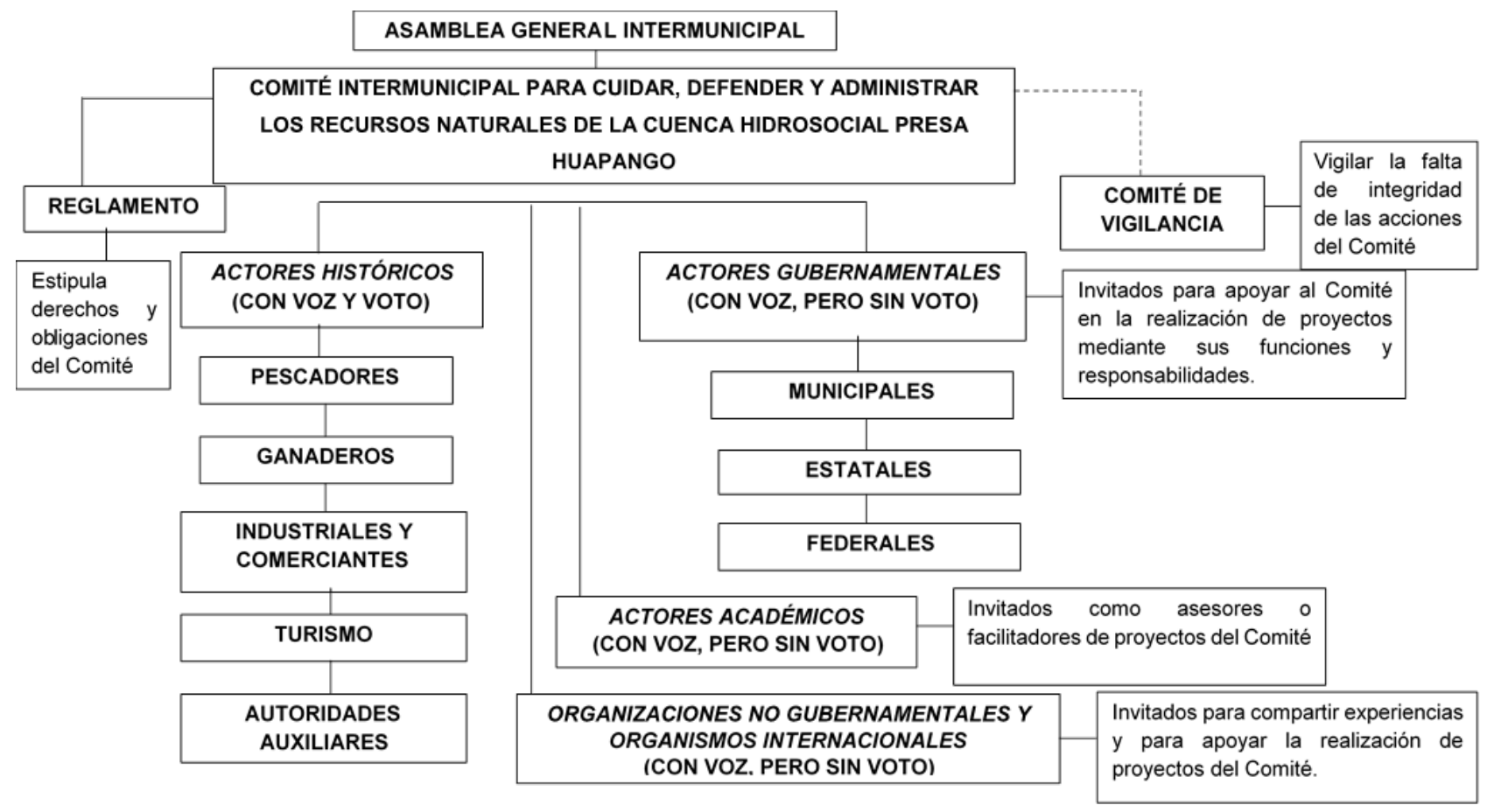

Fuente: Elaboración propia con base en el trabajo de campo y gabinete, García, 2013. 


\section{CONCLUSIONES}

Los cuerpos de agua compartidos a nivel mundial presentan problemas de carácter ambiental, social, económico y político que deben ser atendidos desde un enfoque de gestión integrada de los recursos hídricos y de gobernanza, ya que es ahí donde las estructuras históricas permiten la cooperación de los distintos actores para resolver problemas comunes.

Por lo que la definición teórico-social de los principales términos de la GIRH y la gobernanza permiten entender la estructura sociohistórica de la región del cuerpo de agua compartido como unidad de análisis para la interpretación de la información con trabajo de campo, donde se pueden detectar los principios de democracia, voluntariedad de la sociedad, autogestión, identidad, cooperación, cultura, poder, participación social y relaciones intermunicipales a nivel regional como factores clave de la gobernanza.

En este sentido, se identificó que un cuerpo de agua compartido debe ser analizado desde un enfoque de cuenca hidrosocial, ya que las estructuras sociopolíticas históricas que se tejen en torno al agua, generan redes de interrelación entre los actores de aguas abajo y aguas arriba, lo que permite la vinculación social para llegar a acuerdos democráticos que solucionen los problemas comunes.

Además, se confirmó que el trabajo de campo juega un papel primordial para la obtención de datos de primera mano recogidos in situ, ya que permite tener un diagnóstico más real de la coyuntura sociopolítica, económica y ambiental para entender la problemática sociopolítica, económica y ambiental generadas a través del tiempo en las regiones.

Se detectó el estudio de la historia como explicación teórico social de causa-efecto y no como cronología de los hechos históricos, lo cual permitió identificar las estructuras sociopolíticas y a los actores históricos consolidados en la región.

Se identificó que sí bien la GIRH y la gobernanza no son lo mismo, éstas se encuentran unidas mediante la conjugación de las cuatro vertientes que atiende cada una de ellas: ambiental, social, económica y política, por lo que su complementariedad resulta evidente en el análisis de cuerpos de agua compartidos, ya que éstas deben ser elaboradas en un contexto holístico de la realidad mediante una serie de principios coyunturales y contextuales.

Se concluyó que los gobiernos municipales en México no tienen la facultad legalmente expresa en el artículo 115 de la Constitución Política de los Estados Unidos Mexicanos para asociarse intermunicipalmente en torno al cuidado de los recursos naturales y el medio ambiente, por lo que son los ciudadanos de los municipios los que pueden asociarse por medio del derecho consuetudinario (usos y costumbres) y mediante las facultades de libre asociación que les otorga la Ley Agraria a los Ejidatarios para hacer frente a su problemática intermunicipal común de forma democrática y participativa.

Se identificó que no existe una solución homogénea o universal para los problemas del agua en el mundo, sino más bien un conjunto de opciones regionales basadas en la diversidad de estructuras sociales conformadas a través de la historia para entender sus particularidades de cada una de ellas.

En esta investigación se propuso la creación de un Comité Intermunicipal con su Reglamento para el cuidado de los recursos naturales de la $\mathrm{CHPH}$, ya que el simple análisis de la problemática, no contribuye en la solución de los problemas sociopolíticos, ambientales y económicos de la región, como sí lo hace el diseño de instrumentos de planeación para contribuir en la realización de acciones, programas y proyectos para el desarrollo regional.

Se concluyó que la vinculación de las ciencias sociales con el trabajo de campo permite la sistematización de los problemas ambientales, sociales, políticos y económicos a través de la simplificación de la realidad mediante instituciones ciudadanas que permiten diseñar y aplicar políticas públicas territoriales, planes, programas y proyectos que incidan directamente en la solución de los problemas que aquejan a las regiones de los países y del mundo en general.

Finalmente, cabe destacar que el proceso metodológico que se usó en esta investigación, puede ser la referencia o el punto de partida para el análisis de otros cuerpos de agua y recursos naturales compartidos a nivel internacional, nacional, regional y local desde una perspectiva integral considerando los aspectos sociales, políticos, ambientales y económicos que permitirán abordar la problemática desde una visión interdisciplinaria y mediante una triangulación del marco teórico, el trabajo de campo y el uso de indicadores numéricos.

\section{BIBLIOGRAFÍA}

Aguilar Rojas, G. e Iza, A. 2009: Gobernanza de aguas Compartidas. Aspectos jurídicos e institucionales, San José, Costa Rirca, UICN Oficina Regional de Mesoamérica.

Atkinson, P.; Coffey, A.; Delamont, S. Lofland, J. \& Lofland, L. (eds.) 2001: Handbook of ethnography. Thousand Oaks (Califormia), SAGE Publications Inc, https://doi.org/10.4135/9781848608337

Bonnal, J. 1996, Les acteurs et leur stratégies vis-à-vis des ressources naturelles: réflexion méthodologique. Land reform, 1996. Informe preparado para el Servicio de instituciones rurales y de participación (SDAR) de la FAO. s. d.

Centro para el Agua y el Medio Ambiente 2014: "Integrated Water Resources Management in Action”, WWAP, DHI Water Policy, PNUMA, http://www.un.org/spanish/waterforlifedecade/iwrm.shtml, 12-09-2015.

Cernea, M. 1995: Primero la gente. Variables sociológicas en el desarrollo rural, México, Fondo de Cultura Económica.

Chávez, A. y Guadarrama J. 2004: "La región central de México en transición: tendencias económicas y migratorias a finales del milenio”, en Adrián Aguilar (coord.), Procesos metropolitanos y grandes ciudades. Dinámicas recientes en México y otros países. México, $\mathrm{H}$. Cámara de Diputados, LIX Legislatura, Instituto de Geografíacrimpuec-unam-conacyt-Miguel Ángel Porrúa, 147-187.

Comisión del Agua del Estado de México (CAEM), 2002: Principales cuerpos de agua y su calidad. S. d. http://www.edomexico.gob.mx/, 303-2013.

Comisión Nacional del Agua (Conagua), 2009: Tabla maestra de presas. s. d. http://conagua.org.mx/, 4-04-2013.

Cotler, H. 2004: El manejo integral de cuencas en México, Estudios y reflexiones para orientar la política ambiental. México, Secretaría de Medio Ambiente y Recursos Naturales, Instituto Nacional de Ecología.

Cotler, H. y Caire, G. 2009: Lecciones aprendidas del manejo de cuencas en México. México, Secretaría de Medio Ambiente y Recursos Naturales. 
Díaz, C. 2015: “Gobernabilidad del Agua e Instituciones” documento presentado en el Curso Integridad y Transparencia de la Gestión de Agua en México, Universidad Autónoma de Nuevo León, Monterrey, México, 3 al 6 de noviembre.

Estrada, I. J., Oropeza, M. M. y García, R. 2011: “Daños colaterales de las carreteras", Valor Universitario, 2(17).

FAO (Organización de las Naciones Unidas para la Alimentación y la Agricultura) 2004: "Departamento de Pesca y Acuicultura", http://www.fao.org/fishery/countrysector/, 4-09-2019.

Galindo, J. A. y Jiménez, A. 2018: "Gobernanza del Agua en México", Asociación Nacional de Empresas de Agua y Saneamiento (ANEAS), México, http://aneas.com.mx/gobernanza-del-agua-en-mexico/, 12-062018.

Gallego, I., García, D. y Cervantes, I. 2012: Implementación de Acciones de Ordenamiento de la Pesca Ribereña en los Embalses de Taxhimay, Miguel Alemán Y Huapango del Estado de México, Facultad de Ciencias, Centro de Investigación en Recursos Bióticos, UAEMex, México.

García, M. (2013), “Trabajo de campo (2013-2015)”, CIRA, México.

Global Water Partnership (GWP) 2006: "Implementación de la Gestión Integrada de los Recursos Hídricos”, Documento temático, eje 2. IV Foro Mundial del Agua, México.

Global Water Partnership (GWP) 2009: "Integrated Water Resources Management in Practice: Better Water Management for Development”, http://www.gwpforum.org/, 12-02-2014.

H. Ayuntamiento de Aculco 2009: Plan de Desarrollo Municipal 20092012. México Dirección de Planeación, Evaluación y Seguimiento, Aculco.

H. Ayuntamiento de Timilpan 2009, Plan de Desarrollo Municipal 20092012. México Dirección de Planeación, Evaluación y Seguimiento, Timilpan.

Harris, J. 2001: "How Much Difference does Politics Make? Regime Differences Across Indian States Rural and Poverty Reduction", Working Paper Series, No. 00-01, lse Development Studies Institute, Londres.

Insituto Nacional para el Federalismo y el Desarrollo Municipal (Inafed) 2013: "Enciclopedia de los Municipios y delegaciones de México", http://www.inafed.gob.mx/, 20-08-2015.

Instituto Mexicano para la Competitividad, A. C. 2014: en http://www.comparadondevives.org/, 5-09-2019.

Instituto Nacional de Estadística e Informática (INEGI), 2010: Censo de Población y Vivienda. México, Instituto Nacional de Estadística Geografía e Informática.

Lazos, R. 2006: "Proyecto de gestión ambiental de la cuenca del lago de Pátzcuaro”, en Ávila, P. (Coordinadora), Agua y lagos. Una mirada desde lo global hasta lo local. México, Biblioteca Michoacana.

Leidecker J. \& Bruno A. 1984: "Identifying and Using Critical Success Factors", Long Range Planning, 17(1), 23-32, https://doi.org/10.1016/0024-6301(84)90163-8

Malinowsky, B. 1976: El Método Etnográfico. Los Argonautas del Pacifico Sur, Barcelona, Editorial península.

Maya, D. L.; Castillo, D.; Ramos, P. A. y Roldán, A. M. 2004: “Análisis de la acción colectiva para el Manejo de cuencas Estudio piloto-cuenca de la Presa de Fúquene”, Agencia de Cooperación Técnica Alemana GTZ-, Consorcio para el Desarrollo Sostenible de la Ecorregión Andina CONDENSAN, Corporación Autónoma Regional para el desarrollo sostenible de Cundinamarca, Colombia.
Maya, D. L.; Castillo, D.; Ramos, P. A. y Roldán, A. M. 2004: Análisis de la acción colectiva para el Manejo de cuencas Estudio piloto-cuenca de la Presa de Fúquene, Agencia de Cooperación Técnica Alemana -GTZ, Consorcio para el Desarrollo Sostenible de la Ecorregión Andina CONDENSAN, Corporación Autónoma Regional para el desarrollo sostenible de Cundinamarca, Colombia.

Organización para la Cooperación y Desarrollo Económico (OCDE), 2015: Principios de Gobernanza del Agua de la OCDE. Junta Directiva de Gobernanza Pública y Desarrollo Territorial, https://www.oecd.org/gov/regional-policy/OECD-Principles-Waterspanish, 11-11-2015.

Palerm, Á. 1972: "Ensayo de crítica al desarrollo regional en México”, en Barkin D. (Comp.), Los beneficiarios del desarrollo regional, México, S.E.P./SETENTAS.

Piña, R. 1976: Investigación sobre Huamango y Región Vecina, Volumen I, México, Gobierno del Estado de México.

Programa de las Naciones Unidas para el Desarrollo (PNUD) (2006) Informe Sobre Desarrollo Humano, México, Mundi-Prensa México S.A. de C.V.

Quiroz, F.; Delgadillo, O. y Durán, A. 2012: Aguas arriba, aguas abajo. Luces y sombras de la Gestión Integral de los Recursos Hídricos: Reflexiones desde la investigación aplicada, Bolivia Facultad de Ciencias Agrícolas, Pecuarias Forestales y Veterinarias, Centro Agua, UMSS.

Rogers, P. 2002: “Gobernanza del agua en América Latina y el Caribe”, en Reunión Anual del Banco Interamericano de Desarrollo en Fortaleza, Brasil.

Rogers, P. and Hall, A. (2003), Effective Water Governance, Sweden, Water Partnership, Technical Committee (TEC), Global Water Partnership,.

Romero, A.; Díaz, C.; Martínez, T.; Gómez, M. Á.; Hernández M.; Alberich, M. E.; Mastachi, C. A.; Hinojosa, A. y Becerril R. (2012), La antropología en la planificación regional como elemento para la gestión integrada de los recursos hídricos, México, UAEM.

Unión Europea (2006), "Convenio sobre la protección del Rhin", Documento aprobado por la Unión Europea, http://eurlex.europa.eu/legal-content/, 06-09-2019

Uphoff, N. (1988), "Participatory Evaluation of Farmer Organizations' Capacity for Development Tasks", Agricultural Administration and Extension, 30(1), 43-64, https://doi.org/10.1016/0269-7475(88)90047-5

Uphoff, N. (1995), "Adaptar los proyectos a la gente”, en Cernea, M. M., (coord.), Primero la gente. Variables sociológicas en el desarrollo rural. México, Fondo de Cultura.

Uphoff, N. (1999), "Understanding Social Capital", en Dasgupta, P. \& Serageldin, I. (eds.), Social capital: a multifaceted perspective, Washington D. C., World Bank.

Vilca, O. 2009, “Alerta global. Ríos, lagos y represas se están secando”, en diario Los Andes, http://www.losandes.com.pe/Opinion/20091025/28919.html, 9-082014.

Watts, J. (2015) "La crisis del agua de la Ciudad de México", en The Guardian, https://www.theguardian.com/cities/2015/nov/12/la-crisisdel-agua-de-la-ciudad-de-mexico, 26-06-2018. 